\title{
Ultrastructural Studies on Oocyte Differentiation and Vitellogenesis in the Oocytes of Female Kareius bicoloratus in Western Korea
}

\author{
Je-Cheon Jun', Hee Woong Gang ${ }^{1}$, and ${ }^{\dagger}$ Ki-Young Lee ${ }^{2}$ \\ ${ }^{1}$ National Institute of Fisheries Science, Busan 46083, Korea \\ ${ }^{2}$ Faculty of Marine Applied Biosciences, Kunsan National University, Gunsan 54150, Korea
}

\begin{abstract}
Ultrastructural studies on oocyte differentiation and vitellogenesis in the oocytes of female Kareius bicoloratus were investigated by transmission electron microscopy. The Golgi complex in the cytoplasm is involved in the formation of yolk vesicles that contain yolk carbohydrates in the yolk vesicle of oocytes in the early vitellogenic phase. In this phase, many pinocytotic vesicles (PVs), which are formed by pinocytosis, contain yolk precursors (exogenous substances). These substances are associated with exogenous heterosynthetic vitellogenesis. In yolked oocytes in the late vitellogenic phase, two morphologically different bodies, which formed by modified mitochondria, appear in oocytes. One is a multivesicular body (synthesized by autosynthetic vitellogenesis), and the other is a yolk precursor (an exogenous substance formed by heterosynthetic vitellogenesis). The multivesicular bodies (MVB) are taken into the yolk precursors (YP) and are transformed into primary yolk globules. However, after the YP mix with exogenous PVs near the zona pellucida, they are transformed into primary yolk globules. Vitellogenesis of this species occurs via endogenous autosynthesis and exogenous heterogenesis. Vitellogenesis occurs through endogenous autosynthesis, which involves the combined activity of the Golgi complex, mitochondria and MVB formed by modified mitochondria. However, heterosynthesis involves pinocytotic incorporation of extraovarian precursors (such as vitellogenin in the liver) into the zona pellucida (via granulosa cells and thecal cells) of the yolked oocyte.
\end{abstract}

Key words : Kareius bicoloratus, Oocyte differentiations, Vitellogenesis

\section{INTRODUCTION}

The stone flounder, $K$. bicoloratus, is a coast-settled species that spawns during the winter season and is distributed along the coasts of Korea, China and Japan (Kim et al., 2005). In Korea, this species is mainly found in coastal waters in western Korea. It is an edible fish and a commercially important resource for fisheries. In particular, due to the recent sharp reduction in standing stock, this fish has been noted as a possible organism for commercial aquaculture. To maintain the reproduction and propagation of natural living resources, it is important to understand the reproductive biology associated with oocyte differentiation and yolk formation (vitellogenesis) during oogenesis. However, comprehensive ultrastructural studies of teleost fish oogenesis by observations from electron microscopy in Korea have been reported for a relatively small number of species, mainly those of economic importance, including Agrammus agrammus (Chung \& Lee, 1985), Sebastes schlegeli (Chung \& Chang, 1995), Hexagrammos otakii (Kang et al., 2004) and Boleophthalmus pectinirostris (Chung et al., 2009). To date, there have been several stud-

\footnotetext{
Manuscript received July 3, 2018, Received in revised form August 1, 2018, Accepted August 27, 2018

$\uparrow$ Corresponding Author : Ki-Young Lee, Faculty of Marine Applied Biosciences, Kunsan National University, Gunsan 54150, Korea. Tel: +82-63-4691832, Fax: +82-63-469-7441, E-mail: leekiy@kunsan.ac.kr
}

This is an Open Access article distributed under the terms of the Creative Commons Attribution Non-Commercial License (http:// creative-commons.org/licenses/by-nc/3.0) which permits unrestricted non-commercial use, distribution, and reproduction in any medium, provided the original work is properly cited. 
ies on reproduction in K. bicoloratus, including reproductive ecology (Jun 2003; Jun et al., 2006), egg and larval development (Kim, 1982; Kim \& Han, 1989; Han \& Kim, 1997a; Jun et al., 2002) and growth and maturity (Mori et al., 1986; Chen et al., 1992; Uehara \& Shimizu, 1999), and egg and larval development (Minami, 1984; Jun et al., 1999a). In addition, there are studies on this species regarding several aspects of ecology, including development of larvae and juveniles (Han \& Kim, 1997b), feeding (Choi, 2000), and on aquaculture, including the technical production of seedling development (Jun et al., 1999b, 2000, 2001), Even though the reproductive ecology of this species has been investigated, its mechanisms of reproduction remain to be fully elucidated. There is limited information available on the oocyte differentiation and the process of vitellogenesis during oogenesis of this species. Recently, it has been shown that the mechanism of vitellogenesis in some fishes occurs through the processes of endogenous autosynthesis and exogenous heterosynthesis (Chung \& Chang, 1995). The formation, accumulation and secretions of several special endocrinological substances for gametogenesis show cyclic changes by the regulation of GTH from the pituitary gland according to the control of external or internal environmental factors ( $\mathrm{Ng}$ et al., 1986). However, the mechanism of vitellogenesis during reproduction in this fish remains unclear. Therefore, it is necessary to study vitellogenesis and the functions of the cellular organelles in the oocytes during oogenesis in the winter-spawning fish. Therefore, the present study used cytological methods to examine oocyte differentiation and the processes of vitellogenesis during oogenesis in $\mathrm{K}$. bicoloratus. The results provide information regarding the mechanism of vitellogenesis in the ovary by electron microscopic observations.

\section{MATERIALS AND METHODS}

\section{Sampling methodology}

The stone flounder, K. bicoloratus were collected mon- thly by the trawl net at the coastal waters between Gyeongryelbiyeoldo, Taean-Gun, Chungcheongnam-do, Korea from January to December 2008 (Fig. 1). After the live fishes were transported to the laboratory, their total lengths and standard length were measured using a ruler.

\section{Ultrastructure of oocyte differentiation and vitel-} logenesis during oogenesis

A total of 80 females were used for ultrastructural studies of germ cell differentiation and vitellogenesis in the oocytes during oogenesis by electron microscopy. With respect to the production of tissue specimens for transmission electron microscopy, excised samples of gonads were cut into small pieces and immediately fixed in $2.5 \%$ paraformaldehyde-glutaraldehyde in $0.1 \mathrm{M}$ phosphate buffer (pH 7.4) for $2 \mathrm{~h}$ at $4^{\circ} \mathrm{C}$. After prefixation, the specimens were washed several times in the buffer solution and then postfixed in $1 \%$ osmium tetroxide solution in $0.2 \mathrm{M}$ phosphate buffer ( $\mathrm{pH} \mathrm{7.4)}$ for $1 \mathrm{~h}$ at $4^{\circ} \mathrm{C}$. The specimens were then dehydrated in increasing concentrations of ethanol,

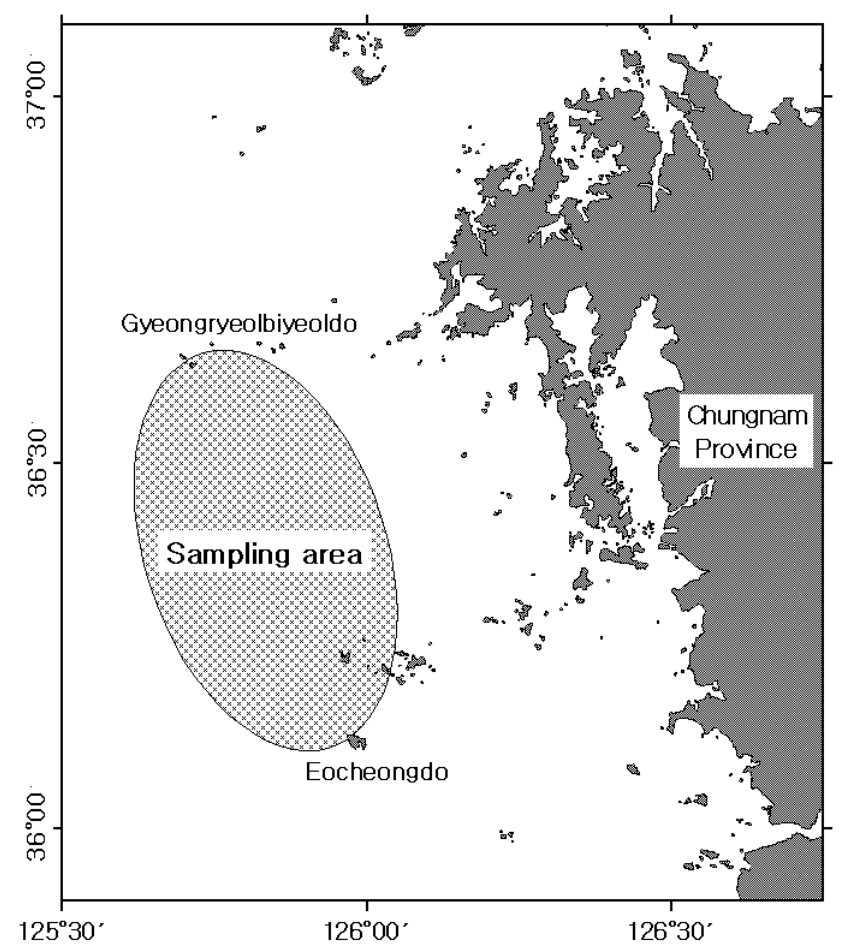

Fig. 1. Map showing the sampling area. 
cleared in propylene oxide, and embedded in Epon-812. Ultrathin sections of Epon-embedded specimens were cut to a thickness of $80-100 \mathrm{~nm}$ with a LKB ultramicrotome. The sections were mounted on collodion-coated copper grids, double stained with uranyl acetate followed by lead citrate, and observed under a JEM 100 CX-2 (80 kv) electron microscope.

\section{RESULTS}

Based on the morphological and ultrastructural characteristics of oocytes by electron microscopic observations, the developmental phases of the oocytes during oogenesis can be classified into four phases: (1) the oogonial phase, (2) the previtellogenic phase, (3) the vitellogenic phase, and (4) the mature phase.

In addition, the ultrastructure of the granulose cells and thecal cells, which are supply of exogenous substances, that are attached to the oocytes associated with vitellogenesis were investigated. Ultrastructural characteristics of oocyte development, granulosa cells and thecal cells in each stage during oogenesis are as follows:

The oogonial phase: During this phase, the oogonia occurred on the germinal epithelium of the ovarian lobules. An oogonium has a nucleolus in the nucleus, and several mitochondria and vacuoles appeared in the cytoplasm (Fig. 2A).

The previtellogenic phase: The oogonial phase developed into the previtellogenic phase by the first prophase of meiosis. The oocytes in the previtellogenic phase can be divided into two forms of oocytes according to the characteristics of oocyte development: 1) the chromatin nucleolus oocyte, and 2) the perinucleolar oocyte.

1) The chromatin nucleolus oocytes $(20-100 \mu \mathrm{m}$ in diameter) contained a large chromatin nucleolus in the nucleus, and a few mitochondria or several intermitochondrial cements appeared around the perinuclear region in the cytoplasm (Fig. 2B). However, at this time the granulosa cells and thecal cell layers on the vitelline envelope of this oocyte were still not observed.

2) The perinucleolar oocytes (approximately 140-170 $\mu \mathrm{m}$ in diameter) contained several perinucleoli along the nuclear envelope, and a few mitochondria and several intermitochondrial cements appeared around the perinuclear region in the cytoplasm. Notably, the granulosa cells were prominently observed on the vitelline envelope of the perinucleolar oocytes (Fig. 2C, 2D). At this phase, the morphological characteristics of nucleoli appeared round or oval in shape. In particular, a nucleolus, which is composed of granular and fibrillar components, appeared in the nucleus (Fig. 2E).

The vitellogenic phase: Development of previtellogenic phase proceeds into the vitellogenic phase. The vitellogenic phase can be divided into two vitellogenic phases: the early and late vitellogenic phases. At the same time, two forms of oocytes occurred: 1) the yolk vesicle oocyte in the early vitellogenic phase, and 2) the yolked oocyte in the late vitellogenic phase.

1) Yolk vesicle oocytes (110-310 $\mu \mathrm{m}$ in diameter): During the early vitellogenic phase, the perinuclear oocytes grew to yolk vesicle oocytes. At this time, granulosa cells with slender nuclei, the basement membrane (BM) and the thecal cells appeared clearly. Notably, the protoplasmic processes began to form on the vitelline envelope. Proteinaceous substances appeared around the cytoplasm of the granulosa cell, and a number of microvilli became present on the vitelline envelope of the early vitellogenic oocyte (Fig. 2F). Then, proteinaceous substances in the pinocytotic vesicles and coated vesicles appeared by pinocytosis in the cytoplasm of the yolk vesicle oocyte near the granulosa cell (Fig. 2F, 2G). In particular, the microvilli of the zona pellucida protruded into the cytoplasmic space, and their morphology was irregular, i.e., from straight to curved, etc. Around the border of the zona pellucida, PVs and coated vesicles appeared (Fig. 2G). In the yolk vesicle oocyte, the occurrence of the Golgi complex appeared in the cytoplasm. The Golgi complex was mainly located adjacent to 

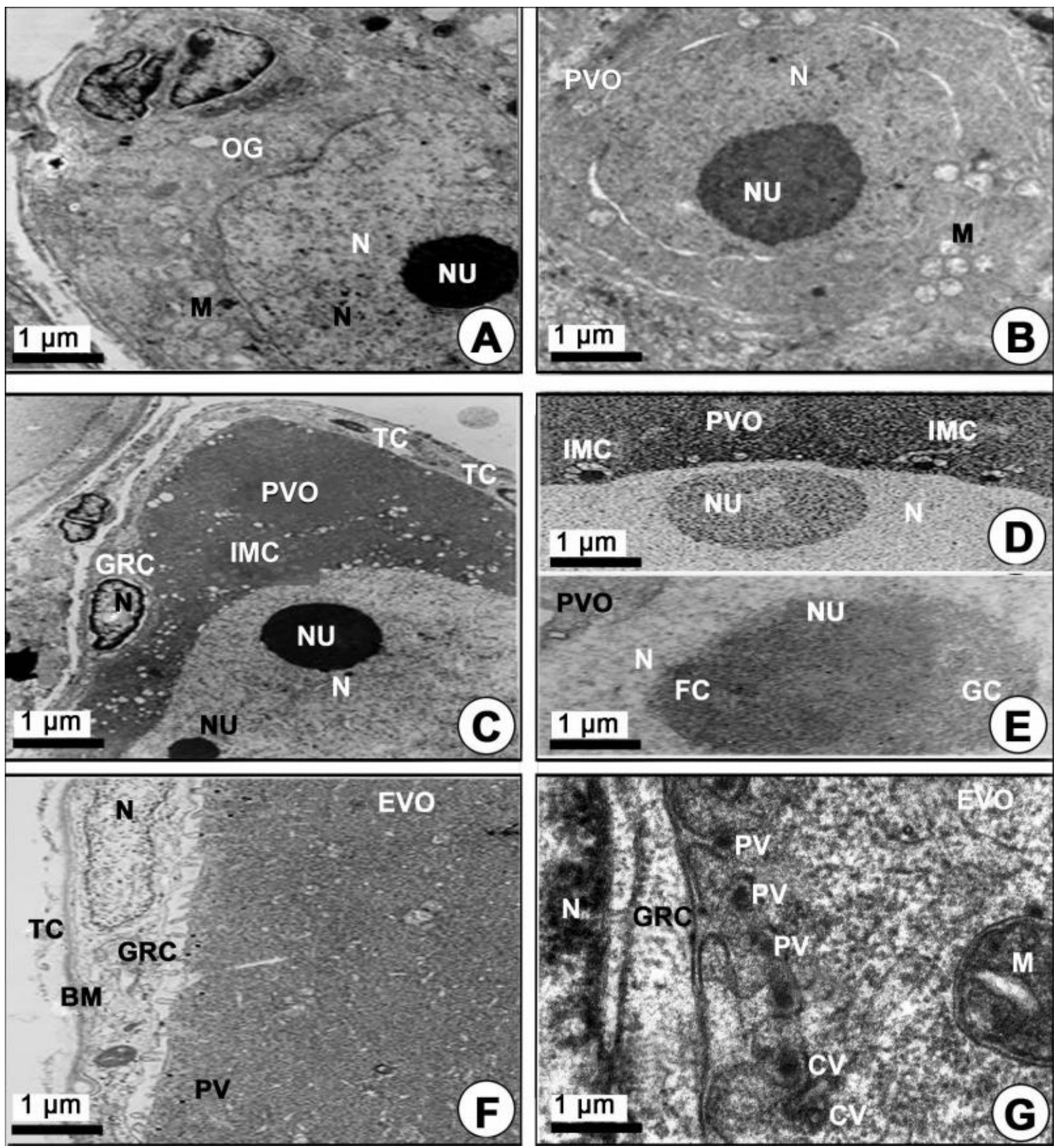

Fig. 2. Transmission electron micrographs of oogenesis in female Kareius bicoloratus (A-F). (A) Oogonium in the oogonial stage. Note a nucleolus in the nucleus and several mitochondria (M) in the cytoplasm; (B) A previtellogenic oocyte (PVO): a chromatin nucleolus oocyte. Note a nucleolus (NU) in the nucleus (N) and several mitochondria (M); (C) A previtellogenic oocyte (PVO): perinuclear oocyte. Note a nucleolus (NU) in the nucleus (N), several mitochondria (M) and intermitochondrial cement (IMC) in the cytoplasm, a nucleus in the granulosa cell (GRC) and the thecal cell layers; (D) A previtellogenic oocyte (PVO). Note a nucleolus (NU) in the nucleus (N) and intermitochondrial cements (IMC); (E) A previtellogenic oocyte (PVO). Note a nucleolus (NU) is composed of a fibrillar component (FC) and a granular component (GC); (F) An early vitellogenic oocyte (EVO), granulosa cell (GRC) and thecal cell (TC). Note a pinocytotic vesicle (PV) in the cytoplasm, nucleus in the granulosa cell (GRC), the basement membrane (BM) and thecal cells (TC); (G) An early vitellogenic oocyte (EVO) and a granulosa cell (GRC). Note several PVs and several coated vesicles (CV) in the cytoplasm and a granulosa cell (GRC). 
the yolk vesicle. Especially the Golgi vacuoles and Golgi vesicles appeared near the yolk vesicle so that these seemed to be related to the formation of the yolk vesicle. The Golgi complex, with the Golgi vacuole and the Golgi vesicle, appeared near the yolk vesicles (Fig. 3A). In addition, a few yolk vesicles formed by the Golgi complex in the cytoplasm around the zona pellucida. The yolk vesicles were observed near the Golgi complex in the cytoplasm of in the yolk vesicle oocyte containing the yolk vesicles (approximately $1.1-2.5 \mu \mathrm{m}$ in diameter). These yolk vesicles were enclosed by the limiting membrane. The inner side of these vesicles is filled with many glycogen particles that show low electron density. As the early vitellogenic oocytes develop, the number and size of the yolk vesicles in the cytoplasm increased. Thereafter, glycogen particles, which were carbohydrate-type yolk precursors, accumulated in the yolk vesicle (Fig. 3B). As development of the yolk vesicle oocytes proceeded and when the oocytes grew to $180-210 \mu \mathrm{m}$ in diameter, the granulosa cells and thecal cells surrounding the yolk vesicle vitelline envelope of the oocytes became distinct by the BM. An elongated nucleus in the granulosa cell, including a granule and several mitochondria in the cytoplasm, were observed. At this phase, a large blood cell (erythrocyte) appeared in the inner thecal cell (ITC; Fig. 3C). As development of early the vitellogenic oocytes proceeded, a large quantity of carbohydratetype yolk precursors (YP) converted into lipid droplets near several mitochondria (Fig. 3D).

2) Yolked oocytes $(400-500 \mu \mathrm{m}$ in diameter): During the late vitellogenic phase, the yolk vesicle oocytes grew to become the yolked oocytes. In the yolked oocyte, the vitelline envelopes of the oocytes formed a thicker zona pellucida. At this time, proteinaceous substances in the granulose cell passed into the ooplasm through the micropores of the zona pellucida of the yolked oocyte (Fig. $3 \mathrm{E})$. At this time modification of several mitochondria was observed in the cytoplasm of the oocytes. As a consequence of the modification of the mitochondrial cristae, several multivesicular bodies (MVB) formed. At this time, the sizes of MVB, which were round or oval in shape, were approximately $1.5-3.0 \mu \mathrm{m}$ in diameter, and each of them has a limiting membrane (Fig. 3F, 4A). Several modified mitochondria combined to form the MVB near the rough endoplasmic reticulum (Fig. 4A). Two morphologically different bodies, which were formed by modified mitochondria, appeared in the yolked oocyte during vitellogenesis: 1) the multivesicular body, and 2) the yolk precursors. The MVB appeared near the primary yolk globules (Fig. 4B). In the yolked oocytes, a capillary vessel in the cell of the ITC layer of the oocytes developed to make a red blood cell (RBC) appear. In the cytoplasm of the oocyte, MVB again combined to form the yolk precursor (Fig. 4C). Because the zona pellucida developed rapidly, the thick zona pellucida can be divided into two parts: 1) the outer and 2) the inner zona pellucida. In the cytoplasm of the late vitellogenic oocyte (LVO), these primary yolk globules mixed with each other to become secondary yolk globules under the inner zona pellucida. The welldeveloped outer and ITC layers, BM, and a granulosa cell layer appeared on the outer zona pellucida (Fig. 4D).

3) Mature phase: As development of the yolked oocyte proceeded, the oocytes containing secondary yolk globules developed into mature oocytes (containing mature yolk globules) during the maturation phase. In mature oocytes or ripe ova (600-700 $\mu \mathrm{m}$ in diameter), growth of the zona pellucida in oocytes led to a thick zona pellucida composed of 6-layer structures between the outer layer and the inner layer of the zona pellucida. However, the several micropores (pits) on the outer zona pellucida were still found. In the cytoplasm of oocytes, lamellar structures near the primary yolk granules (PYG) appeared to be involved in the formation of the tertiary yolk globules. At this phase, the tertiary yolk globules were observed in the cytoplasm of the oocytes (Fig. 4E). Proteinaceous granular and lipid granular substances were observed in the granulosa cell on the thick zona pellucida. The thecal cell layers 

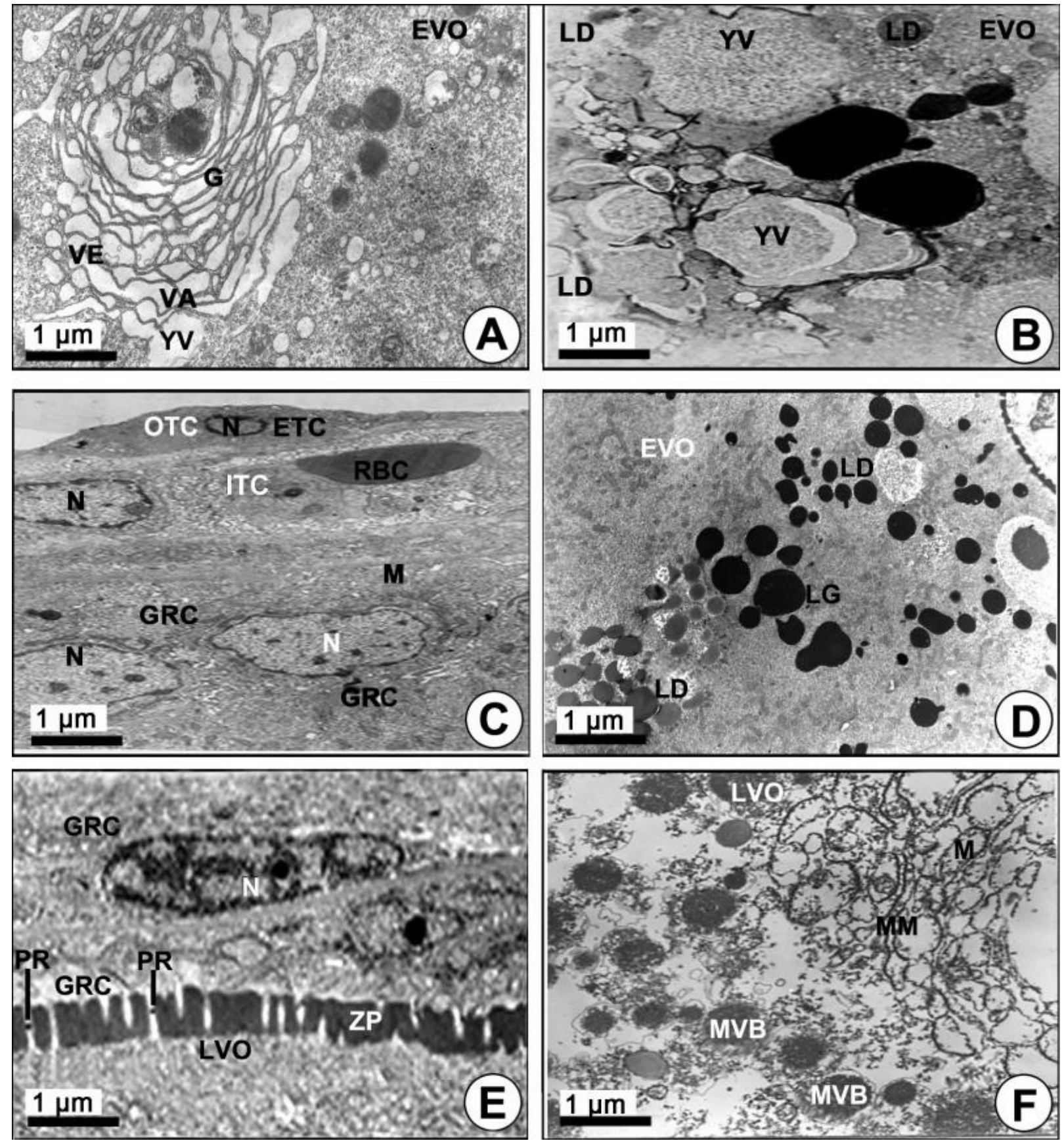

Fig. 3. Electron micrographs of vitellogenesis during oogenesis in female Kareius bicoloratus (A-F). (A) An early vitellogenic oocyte (EVO). Note the Golgi complex (G) being composed of the Golgi vacuole (VA), and the Golgi vesicles (VE) near the yolk vesicles (YV); (B) An early vitellogenic oocyte (EVO). Note lipid droplets (LD), and several yolk vesicles (YV) containing carbohydrates; (C) An early vitellogenic oocyte (EVO). Note the outer thecal cells (OTC) and the inner thecal cells (ITC) containing the red blood cell (RBC), nuclei (N) and mitochondria (M) in several granulosa cells (GRC) on the zona pellucida (ZP); (D) An early vitellogenic oocyte (EVO). Note lipid droplets (LD) and lipid granules (LG) in the cytoplasm of the oocyte; (E) A LVO. Note proteinaceous substances (PR) near the nucleus (N) in the granulosa cell (GRC) passing into the pits of the zona pellucida (ZP) of the LVO; (F) A LVO and formation of several multivesicular bodies (MVB). Note the modification of mitochondria and formation of the MVB in the cytoplasm of the late vitellogenic oocyte (LVO). 

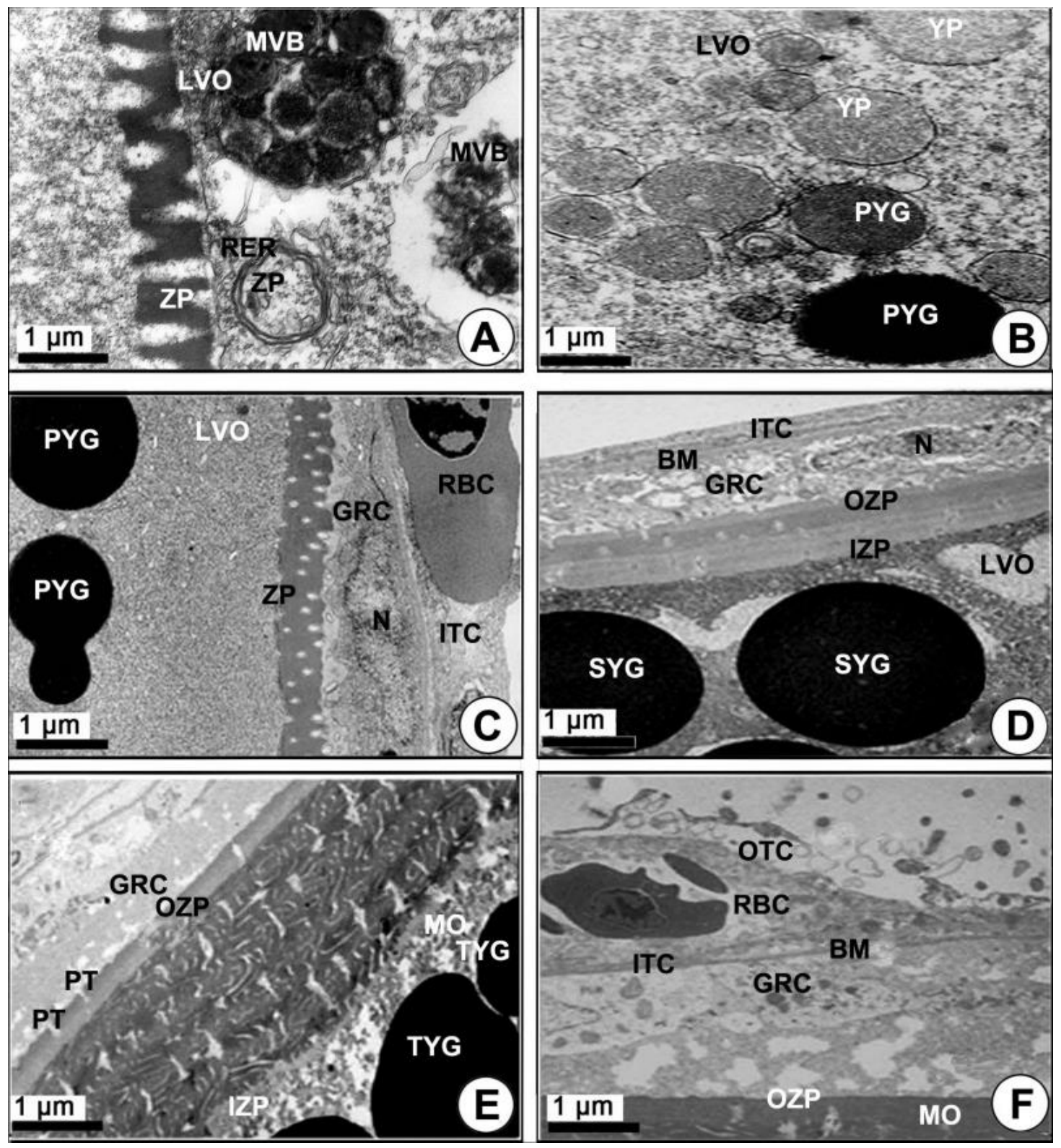

Fig. 4. Electron micrographs of oogenesis in female Kareius bicoloratus (A-F). (A) Formation of several multivesicular bodies (MVB). Note several MVB formed by the modified mitochondria with endoplasmic reticulum (RER) in the cytoplasm of the oocyte; (B) Formations of the yolk precursors (YP) and the primary yolk granules (PYG) in the cytoplasm of LVO. Note several yolk precursors having a prominent uneven and discontinuous limiting membrane and the PYG near the zona pellucida; (C) Formation of PYG in LVO and the granulosa cells (GRC) and a red blood cell (RBC) in the inner thecal cell (ITC). Note pinocytotic vesicle (PV) near the primary yolk attaching to the PYG; (D) Formation of secondary yolk granules (SYG) in LVO with the well-developed zona pellucida. Note the SYG with the zona pellucida, which is composed of the outer and inner layers of the zona pellucida, and the basement membrane (BM) is found between the granulosa cell and ITC; (E) An oocyte in the mature phase. Note a number of secondary and tertiary yolk granules in the cytoplasm of the oocyte and six layers between the outer and inner layers of the zona pellucida and follicular layers, which is composed of the granulosa cell layer, theca externa and internal layers; (F) Before-spawning follicular tissue and oocyte in the maturation phase. Note the appearance of detached thecal cells and the outer layer of the zona pellucida with the closed pits. 
(outer and ITCs) on the BM continued to develop. When oocytes reached over $600-700 \mu \mathrm{m}$ in diameter, it was observed that the accumulation of the yolk substances was completed. The homogeneous membrane of the outer layer of the zona pellucida was closed, and the granulosa cells and thecal cell layers separated from the zona pellucida of mature oocytes (ripe ova) (Fig. 4F). At this time, the fully mature yolk globule of mature oocyte was composed of three components: (1) the main body, (2) the superficial layer, and (3) the limiting membrane. The main body had a high electron density. A small yolk globule had one main body, while a large yolk globule had two or more main bodies showing irregular forms. The main body showed a crystalline form (Fig. 5A). After fully ripe oocytes were completed, highly electron dense protein substance droplets appeared in the cytoplasm of the inner and outer thecal cell layers. The protein droplets may be composed of protein-lysis enzyme that is present prior to the ovulation of mature or ripe ova (Fig. 5B).

\section{DISCUSSION}

In general, the organization of the teleost ovary is varia- ble, and the ovaries can be classified into two basic conditions by the anatomical deposition of the germinal tissue: 1) the gymnovarian condition and 2) the crystovarian condition (Jun, 2003; Kang et al., 2004; Chung et al., 2009). The structures of $K$. bicoloratus and B. pectinirostris belong to the crystovarian condition as seen in $H$. otakii (Kang et al., 2004). The ovary of this species is separated into right and left ovaries, and the separated ovaries are asymmetric in shape. The internal structure of the ovary of this species is composed of several ovarian lobules. A nucleolus was composed of two components VIZ: 1) loosely packed fine granules and 2) a fibrous component. Miller $(1962,1966)$ described that these two parts contain RNA and protein. The synthesis and accumulation of RNA took place in the loose and granular part. Therefore, it is assumed that metabolism might be active at this time.

In the previtellogenic oocyte of $K$. bicoloratus, intermitochondrial cements appeared in the cytoplasms of the oocytes having a large chromatin-nucleolus in the nucleus around the nuclear envelope. Billard (1984) reported that mitochondrial groupings are associated with intermitochondrial cements. Therefore, after the appearance of intermitochondrial cements, the number of mitochondria in
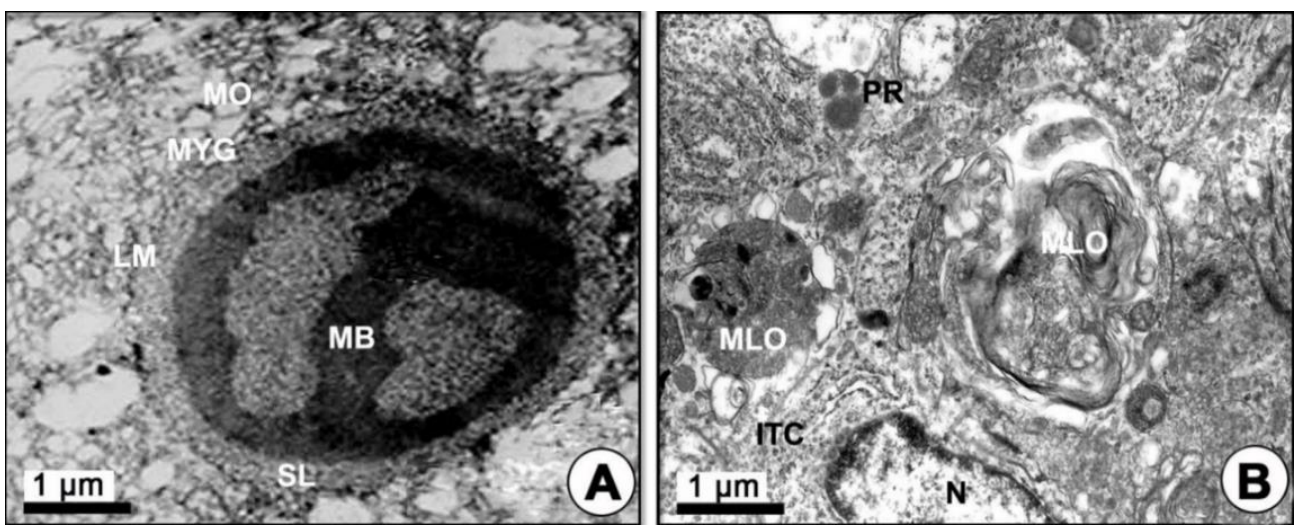

Fig. 5. Electron micrographs showing vitellogenesis during oogenesis in female Kareius bicoloratus (A, B). (A) The morphology of a mature yolk globule in the mature oocyte in the mature phase. Note a mature yolk globule in the mature oocyte crystallized and composed of three parts; the main body (MB), the superficial layer (SL) and the limiting membrane (LM); (B) Just before ovulation follicular tissue of a ripe ovum. Note breakage of the nucleus (N) of the inner thecal cell layers and outer thecal cell layers including several myelin-like organelles (MLO) and proteinaceous substances (PR). 
the early developmental stage of oocytes gradually increased. Thus, the intermitochondrial cements are associated with mitochondrial groupings and the multiplication of the number of mitochondria (Chung et al., 2009). In this study, several large vacuoles appeared near the Golgi complex in the cytoplasm of the previtellogenic oocyte. We believe that large vacuoles were formed by the Golgi vacuoles of the Golgi complex. Previous studies have examined the formation of the yolk vesicle in Sebastes schlegeli; (Chung \& Chang, 1995) and H. otakii; (Kang et al., 2004). In the present study, several yolk vesicles appeared near large vacuoles or vesicles in the cytoplasm of the early vitellogenic oocyte of $K$. bicoloratus.

As shown in Fig. 3A, large vacuoles, which were formed by the Golgi complex, gave rise to yolk vesicles. Thus, it is assumed that the Golgi complex plays an important role in the formation of yolk vesicles containing carbohydrate yolks in the early vitellogenic oocyte of $K$. bicoloratus. In this study, several large vacuoles appeared near the Golgi complex in the cytoplasm of the previtellogenic oocyte. We believe that large vacuoles were formed by the Golgi vacuoles of the Golgi complex. Previous studies have examined the formation of the yolk vesicle in Sebastes schlegeli; (Chung \& Chang, 1995), H. otakii; (Kang et al., 2004) and $K$. bicoloratus (Jun, 2003). In the present study, several yolk vesicles appeared near large vacuoles or vesicles in the cytoplasm of the early vitellogenic oocyte.

Thus, vitellogenesis of $K$. bicoloratus occurred via endogenous autosynthesis and exogenous heterosynthesis. The process of autosynthesis, involved the combined activity of the Golgi complex, mitochondria and the MVB formed by modified mitochondria. The process of heterosynthesis involved pinocytotic incorporation of extraovarian precursors (such as vitellogenin in the liver) into the zona pellucida (by way of follicle cell layers) of early vitellogenic oocytes.

It is assumed that the Golgi complex plays an important role leading to the formation of yolk vesicles containing carbohydrate yolks in the early vitellogenic oocytes of $B$. pectinirostris (Chung et al., 2009) and K. bicoloratus (Jun, 2003).

From observations in the present study, it is assumed that the well-developed Golgi complex and the mitochondria in the cytoplasm of the early vitellogenic oocyte are involved in the formation of lipid droplets in the cytoplasm, and they are also involved in the occurrence of the initial zona pellucida on the vitelline envelope through the process of autosynthetic vitellogenesis. At this time, a number of PVs appeared in the cytoplasm near the basal region of the zona pellucida. Then, the PVs were filled with exogenous extraovarian substances, such as vitellogenin substances formed in the liver, from the granulosa cells through heterosynthetic vitellogenesis.

In the present study, two morphological different bodies, which formed by the modified mitochondria, notably appeared in the LVO. One was the MVB, which were intermediate products of the first process, and the other was the yolk precursors, which are the intermediate products of the other process (Gupta \& Yamamoto, 1971). The MVB were transformed into the primary yolk globules, while the YP were associated with exogenous primary and secondary PVs near the zona pellucida. After the PVs were taken into yolk precursors, the YP were transformed into the primary yolk globules as seen in zebrafish (Yamamoto \& Oota, 1967). In the K. bicoloratus oocyte, the mitochondria were modified at first into the MVB or YP of yolk globules, and then these two bodies became the primary yolk globules and finally formed mature yolk globules via the secondary and tertiary yolk globules. Thus, it is supposed that MVB and YP have a common origin from mitochondria and a common fate of being transformed into the primary yolk globules (Gupta \& Yamamoto, 1971).

Regarding the pits (or micropores) of B. pectinirostris, Chung et al. (2009) reported that a number of projections of the follicle cell stretched into the pits of the zona radiata of the yolked oocyte during vitellogenesis, while the pits 


\section{J-C Jun, HW Gang, K-Y Lee}

of the zona radiata of mature oocyte (or ripe ova) were closed in the mature stage. In this study, several welldeveloped microvilli of the zona pellucida projected into the granulosa cells during vitellogenesis. Although the zona pellucida was very thick, the microvilli of the zona pellucida of mature oocytes disappeared in the maturation phase. It is assumed that various nutrients cannot move into the zona pellucida of mature oocyte because the pits of the zona pellucida were closed. Therefore, our results showed similar phenomena to those of Chung et al., 2009.

\section{ACKNOWLEDGEMENTS}

This research was supported by a grant from National Institute of Fisheries Science (R2017008).

\section{REFERENCES}

Billard R (1984) Ultrastructural changes in the spermatogonia and spermatocytes of Poecilia reticulata during spermatogenesis. Cell Tissue Res 273:219-226.

Chen D, Liu C, Dou S (1992) The biology of flatfish (Pleuronectinae) in the coastal waters of China. Neth $\mathrm{J}$ Sea Res 29:25-33.

Choi XL (2000) Growth and feeding of juvenile stone flounder, Kareius bicoloratus (Basilewsky) at the estuary of the Nakdong River. Master's Thesis, Pukyong Nat Univ, pp 1-40.

Chung EY, Lee TY (1985) A study on the reproductive cycle of greenling, Agrammus agrammus (Temminck et Schlegel). Bull Nat Fish Univ Pusan 25:26-42.

Chung EY, Chang YJ (1995) Ultrastructural changes of germ cell during the gametogenesis in Korea rockfish, Sebastes schlegeli. J Korean Fish Soc 28:736-752.

Chung EY, Choi KH, Jun JC, Choi MS, Lee KY (2009) Ultrastructural studies on oocyte development and vitellogenesis during oogenesis in female Boleophthalmus pectinirostris. Anim Cells Syst 13:49-57.
Gupta NN, Yamamoto K (1971) Electron microscope study on the fine structural changes in the oocytes of goldfish, Carassius auratus, during yolk formation stage. Bull Fac Fish Hokkaido Univ 22:187-205.

Han KH, Kim YU (1997a) Development of larvae and Juvenile of the stone flounder, Kareius bicoloratus. Bull Mar Sci Inst Yosu Nat Fish Univ 6:39-47.

Han KH, Kim YU (1997b) Larval morphology of stone flounder, Kareius bicoloratus incubation. Bull Jpn Soc Sci Fish 38:33-42.

Jun JC, Kim CH, Kim JS, Kim BG, Kim SU (1999a) Influence of water temperature and salinity on embryonic development of stone flounder, Kareius bicoloratus. Bull Nat Fish Res Dev Inst 56:83-90.

Jun JC, Kim SW, Kim BG, Kim CH, Kim JS (1999b) seedling production technical development experiment of the stone flounder, Kareius bicoloratus. Tech Rep West Sea Fish Res Nat Res Dev Inst, pp 343-349.

Jun JC, Kim BG, Kim CH, Sim DS (2000) Seedling production technical development experiment of the stone flounder, Kareius bicoloratus. Tech Rep West Sea Fish Res Inst Nat Res Dev Inst, pp 353-357.

Jun JC, Kim BG, Co KC (2001) Indoor induction experiment of sexual maturation of the stone flounder, Kareius bicoloratus. Tech Rep West Sea Fish Res Inst, pp $369-374$

Jun JC, Kim CH, Chung EY, Lee CH, Kim BG (2002) Influence of water temperature and salinity on early development of the stone flounder, Kareius bicoloratus from West Sea of Korea. Korean J Ichthyol 14:190197.

Jun JC (2003) A study on reproductive ecology of the stone flounder, Kareius bicoloratus on the west coast of Korea. Ph.D. Dissertation, Kunsan Nat Univ, p 132.

Jun JC, Chung EY, Yang YC (2006) Ultrastructure of germ cells, cyst epithelial cells and interstitial cells during spermatogenesis of the stone flounder, Kareius bicoloratus. Korean J Ichithyol 18:311-318. 
Kang HW, Kwak OY, Chung EY (2004) Ultrastructural study on oogenesis of the greenling, Hexagrammos otaki. Korean J Ichithyol 16:271-281.

Kim IS, Choi Y, Lee CL, Lee YJ, Kim BJ, Kim JH (2005) Illustrated Book of Korea Fishes. Kyo-hak Publish. Co., Seoul, p 478.

Kim YU (1982) On the egg development and larvae of light-eye flounder, Kareius bicoloratus (Basilewsky). J Korean Fish Soc 15:323-328.

Kim YU, Kim KH (1989) Development of larvae and juveniles of the stone flounder, Kareius bicoloratus. Korean J Ichithyol 1:98-108.

Miller OL (1962) Studies on the ultrastructure and metabolism of mucleoli in amphibian oocytes. In: Breese SS (ed), Electron Microscopy. Academic Press, New York.

Miller OL (1966) Structure and composition of peripheral nucleoli of salamander oocytes. Nat Cancer Inst Monogr 23:53-66.
Minami T (1984) The early life history of a flounder $\mathrm{Ka}$ reius bicoloratus. Bull Japan Soc Sci Fish 50:551-560.

Mori K, Tojima T, Tashiro K, Kimura S (1986) Growth and maturity of stone flounder Kareius bicoloratus in ise bay, central Japan. Bull Fac Fish Mie Univ. 13:151161.

Ng TB, Tam PPL, Woo NYS (1986) Sexual maturation in the black seabream, Mylio macrocephalus Teleostei, Sparidae: Changes in pituitary gonadotropes, hapatocytes and related biochemical constituents in liver and serum. Cell Tissue Res 245:207-213.

Uehara S, Shimizu M (1999) Maturity, condition and feeding of stone flounder Kareius bicoloratus in Tokyo bay. Bull Japan Soc Sci Fish 65:209-215.

Yamamoto K, Oota I (1967) An electron microscope study of the formation of the yolk globules in the oocytes of zebrafish, Brachydanio rerio. Bull Fac Fish Hokkaido Univ 17:165-174. 